\title{
The Fibre Damage Due to the Mechanical Cutting of Treated and Untreated Kenaf Short Fibre/Unsaturated Polyester Composite
}

\author{
Ahmad Zafir Romli ${ }^{1,2^{*}}$ and Muhammad Mustakim Mohd Ghaztar ${ }^{2}$ \\ ${ }^{1}$ Centre of Polymer Composites Research and Technology, Institute of Science, \\ Universiti Teknologi MARA, 40450 Shah Alam, Selangor, Malaysia \\ ${ }^{2}$ Faculty of Applied Sciences, Universiti Teknologi MARA, \\ 40450 Shah Alam, Selangor, Malaysia \\ "Corresponding author:ahmad349@salam.uitm.edu.my
}

Published online: 15 April 2017

To cite this article: Ahmad Zafir Romli and Muhammad Mustakim Mohd Ghaztar. (2017). The fibre damage due to the mechanical cutting of treated and untreated kenaf short fibre/unsaturated polyester composite. Journal of Engineering Science, 13: 63-74, https://doi.org/10.21315/jes2017.13.5.

To link to this article: https://doi.org/10.21315/jes2017.13.5

\begin{abstract}
The use of short natural fibre in polymer matrix is common since it would be easier for the processing purposes. The common method used to shorten the fibre is via the pulverisation process. Pulverisation is a size reduction process by means of mechanical cutting using sharp rotating steel blades. However, less attention was given to the effects of this process towards the micro-structural properties of the natural fibre. This study is to trash out the most significant mechanical damage to the treated and untreated, pulverised Kenaf fibre using 0.25 and $5.0 \mathrm{~mm}$ sieve sizes. The micro-structural properties of the fibre were analysed using polarised optical microscope. From the results obtained, it was identified that there are seven types of fibre damage to the Kenaf fibre after passing through the pulverisation processes. These damages are the fibre axial splits, fibrillar failure, granular fracture, fatigue failure, fibre peel off, chemically degraded fibre brake and biaxial failure. By knowing the behaviour and fibre condition, the cause of inconsistency of natural fibre based composite strength can be further discussed.
\end{abstract}

Keywords: Kenaf short fibre, pulverisation process, unsaturated polyester, fibre damage, mechanical damage

\section{INTRODUCTION}

Short fibre can be considered as one of the most favourable fibre systems to be used in the polymer composite for various applications. This is because of the ease of handling and processing. Nevertheless, problems remain and difficulty faced are the anisotropic property and limited wetting ${ }^{1}$ resulting to poor 
disperse-ability of fibre in the composite system. The mentioned problem will lead to variability of the composites properties. ${ }^{2}$

The effect of an anisotropy is more critical in the short fibre composites due to the limitation of the matrix to "hold" the fibre (fibre aspect ratio) and the orientation of the fibre it self. ${ }^{3}$ Hence, increasing the fibre aspect ratio will help in reducing the anisotropicity resulting to more physically and mechanically stable composite. In addition to that, the anisotropy problem in the composite may occur at a much earlier stage - materials preparation process ${ }^{4,5}$ especially for the preparation of short fibre from bio-base sources.

There is a research done by Le Duc et al. ${ }^{2}$ where the scope of their study is focusing on the fibre failure after mixing process. The result identifies the ruptured fibre failure that happened to the flax fibre and fibre length distribution is identical between long kink bands. Apparently, the research results only identify only one type fibre failure after the mixing process whereby there are many possibilities of failure might happened due to fibre size reduction process. ${ }^{6}$

A study conducted by Herrera-Franco and Valadez-Gonzáles ${ }^{7}$ in their single fibre pull-out test shows that henequen fibre treated with both $\mathrm{NaOH}$ and silane produce highest interfacial shear strength with critical length and aspect ratio of 3.5 and $19.44 \mathrm{~mm}$ respectively and the claim was supported by Le Duc et $\mathrm{al}^{2}{ }^{2}$ On the other hand $\operatorname{Kardos}^{8}$ pointed out that that the individual short fibre aspect ratio can be neglected and the most important is bundle short fibre aspect ratio. The fibre-matrix adhesion at interface also can be ignored as the optimisation of fabrication is the most essential to reduce the formation of voids in the sample. ${ }^{8}$

Thus, the aim of this study is to determine mechanical damage to the treated and untreated kenaf fibre due to the pulverisation process as to be incorporated into the unsaturated polyester for the composite fabrication. This study also expected to be one of the efforts for better understanding on the kenaf fibre polymer composites properties and inconsistency towards stronger and greener environmental product in future.

\section{METHODOLOGY}

\subsection{Treatments Process}

The fibre was immersed in $6 \% \mathrm{NaOH}$ for $3 \mathrm{~h}$. The fibre was washed thoroughly with distilled water to remove any excess of $\mathrm{NaOH}$ on the fibre surface. The treated fibre was dried in an oven at $70^{\circ} \mathrm{C}$ for four days. The fibre 
was further treated using aminosilane chemical dissolved in Ethanol and water with the ratio of 1:95:4 respectively for $30 \mathrm{~min}$. The $\mathrm{pH}$ of immersion was controlled in the range of 3.5 to 5.5 using acetic acid. The fibre was again dried in the oven at $70^{\circ} \mathrm{C}$ for four days.

\subsection{Sample Preparation Process}

The completely dried fibre was pulverised into two different lengths; 5 and $0.25 \mathrm{~mm}$ sieve sizes using Fritsch Power Cutting Mill Pulverisette 15. The formulation of fibre loading is as shown in Table 1. The mixing process was carried out by stirring the unsaturated polyester and methyl ethyl ketone peroxide thoroughly prior to the addition of kenaf fibre. The mixture was closed and pressed using hydraulic hot press at $70^{\circ} \mathrm{C}$ for $40 \mathrm{~min}$. The mould was removed and post-cured in oven at $70^{\circ} \mathrm{C}$ for $24 \mathrm{~h}$.

Table 1: The formulations and labelling of samples.

\begin{tabular}{|c|c|c|c|c|c|}
\hline \multirow[t]{2}{*}{ Group } & \multirow[t]{2}{*}{ W/W (\%) } & \multicolumn{2}{|c|}{$\begin{array}{c}\text { A - Fibre category } \\
(7.55 \pm 0.42 \text { aspect ratio }) \\
(0.43 \pm 0.33 \mathrm{~mm} \text { length })\end{array}$} & \multicolumn{2}{|c|}{$\begin{array}{c}\text { B - Fibre category } \\
(7.5 \pm 0.64 \text { aspect ratio }) \\
(2.89 \pm 1.36 \text { mm length })\end{array}$} \\
\hline & & Untreated & Treated & Untreated & Treated \\
\hline \multirow{3}{*}{$\begin{array}{l}\text { Low fibre } \\
\text { loading }\end{array}$} & 5 & 5 FUnA & $5 \mathrm{FTrA}$ & 5 FUnB & $5 \mathrm{FTrB}$ \\
\hline & 10 & 10 FUnA & $10 \mathrm{FTrA}$ & $10 \mathrm{FUnB}$ & $10 \mathrm{FTrB}$ \\
\hline & 15 & 15 FUnA & $15 \mathrm{FTrA}$ & 15 FUnB & $15 \mathrm{FTrB}$ \\
\hline \multirow{3}{*}{$\begin{array}{l}\text { High fibre } \\
\text { loading }\end{array}$} & 45 & $45 \mathrm{FUnA}$ & $45 \mathrm{FTrA}$ & 45 FUnB & $45 \mathrm{FTrB}$ \\
\hline & 50 & 50 FUnA & $50 \mathrm{FTrA}$ & $50 \mathrm{FUnB}$ & $50 \mathrm{FTrB}$ \\
\hline & 55 & 55 FUnA & $55 \mathrm{FTrA}$ & $55 \mathrm{FUnB}$ & $55 \mathrm{FTrB}$ \\
\hline
\end{tabular}

\subsection{Morphological Analysis Process}

The pulverised fibre was put on a glass slide and closed with a glass lid without immersion oil and viewed at $10 \times$ magnification. The technique used to observed the compress sample is call the "in sample focused" where the fibre observed is embedded in the unsaturated polyester not on the surface of the composite panel as shown in Figure 1. 




Figure 1: "In sample focused" using transmitted optical microscope to observed fibre in composite panel: (a) objective lense, (b) sample surface, (c) light source and (d) focused fibre.

\section{RESULTS AND DISCUSSIONS}

\subsection{Pulverised Fibre}

Using optical microscope, there are seven types of fibre damage characteristics to both treated and untreated kenaf fibre was identified. These characteristic may become the cause of failure during mechanical test (stress concentrator). The fibre damage characteristics are the fibre axial splits, granular fracture, fibrillar failure, fatigue failure, fibre peel off, chemical degraded fibre brake and biaxial failure.

Figure 2 shows the complete structure of fibre without subjected to any mechanical damage. It looks like the fibrils were attached one to another strongly. Long axial splits of pulverised fibre (Figure 3[a]) was caused by a small horizontal hole defect in the fibre internally or externally at the fibre. Thus, as higher shear stress build by pulverise rotating blade applied onto the fibre during pulverised process, the hole defect elongate horizontally (Figure 3[a1]) producing fibre separation in the middle part of the fibre. ${ }^{9,10}$ It producing an empty space in the fibre that can cause a reduction in mechanical strength as it create voids that can initiate crack when subjected to stress. ${ }^{11}$ Fibre axial splits that propagate at the fibre edge was presented in Figure 3(b). It was caused by the initiation cut to give bifurcation cracks (Figure 3[a2]) at the edge of fibre. This fibre failure was caused by a certain geometry angle cut, which developed uniformly in inner cracks at the fibre end. ${ }^{9}$ This fibre failure might increase the stress transfer 
efficiency from matrix as it possess wider fibre end area but in the other hand, it can give low strain properties as the branching fibre's end can detached during strain forces applied.



Figure 2: Complete structure of fibre fibrils.

Fibre fibrillar failure happened when fibre was treated with sodium hydroxide and aminosilane, the fibril-fibril interaction were weakened because the presence of moisture ${ }^{9,12}$ even after drying process and due to stress, it initiates crack randomly on the fibre (Figure 3[c]). Figure 4 demonstrated the independent fibrillar break of treated and untreated fibre after pulverisation process. The fibrils begin to break individually as tension were applied onto the fibre as in Figure 4(a). The fibrils breakage were multiplied as prolong tension applied onto the fibre (Figure $4[\mathrm{~b}]$ ). Finally the fibrils bundle were broken (Figure $4[\mathrm{c}]$ ) and forming a cone tip (Figure $4[\mathrm{~d}]$ ) at the fibre end. ${ }^{9,10}$ This type of fibre failure probably can caused low stress retaining ability as low stress transfer efficiency occurred. It was due to low fibre contact area at the tip of the fibre.

Granular fracture that happened onto pulverised fibre was from stepped break failure (Figure 5). It formed initially with an axial split in the middle of the fibre. The breakage process continues with two pre-fracture on two parts of fibre in area of axial split. However, as there was some weak bonding between the fibril in the fibre, the stress was transferred to the neighbouring fibril and finally the fibre completely break. ${ }^{9}$ Granular fracture may leads to faster fibre pull out breakage, it is due to low contact area especially the treated roughen surface that detached from the fibre.

Pulverise process also contributes to fatigue failure of pulverised fibre. The failure was initiated with a transverse crack on fibre (Figure 6[a]). Noted that, transverse crack depths determine the fibre diameter as deeper crack, cause thinner fibre diameter. The crack was split and continually growing parallel to the fibre axis as in Figure 6(b). The separation was getting deeper and detached from the fibre. In the end the fibre reduced in its diameter (Figure 6[c]) or cross-section 
(Figure 6[d]). These failure eventually can cause ductile tensile break fibre failure during composite testing after fabricated with polymer matrix. ${ }^{9,10}$ Fatigue failure can give low elastic properties to the fibre, as fibre with diameter reduction area might be the weak point to the fibre. It can easily detached giving low stiffness properties to the fibre.

(a)

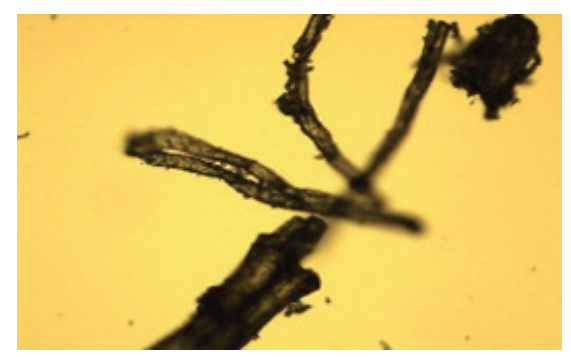

(b)

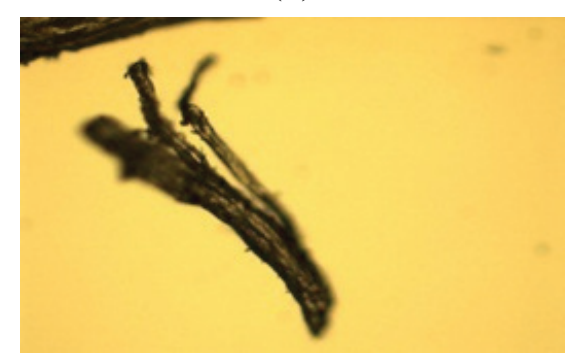

(a1)

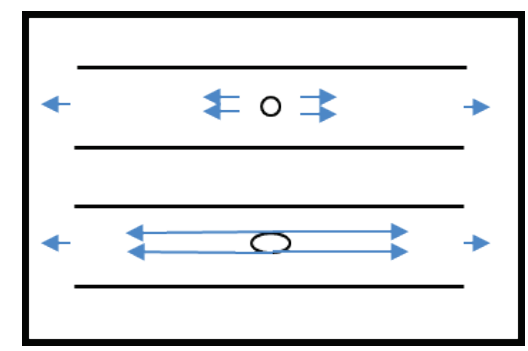

(a2)

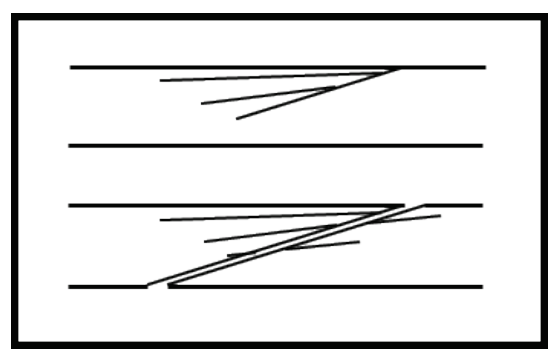

(c)

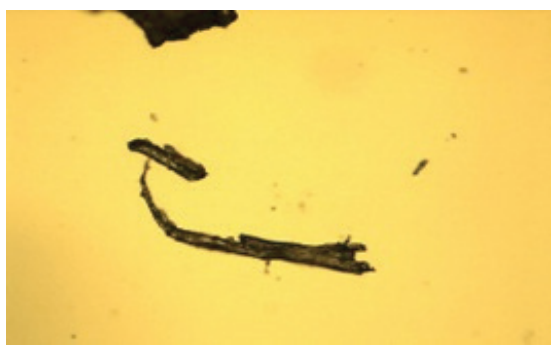

Figure 3: Fibre long axial splits at the middle part (a) and propagated at edge of the fibre, (b) fibre fibrillar failure and (c) using optical microscope with $10 \times$ magnification. Illustrations of horizontal hole elongates as (a1) prolong shear stresses increases and (a2) different split propagation pattern at both broken fibre. $^{9}$ 


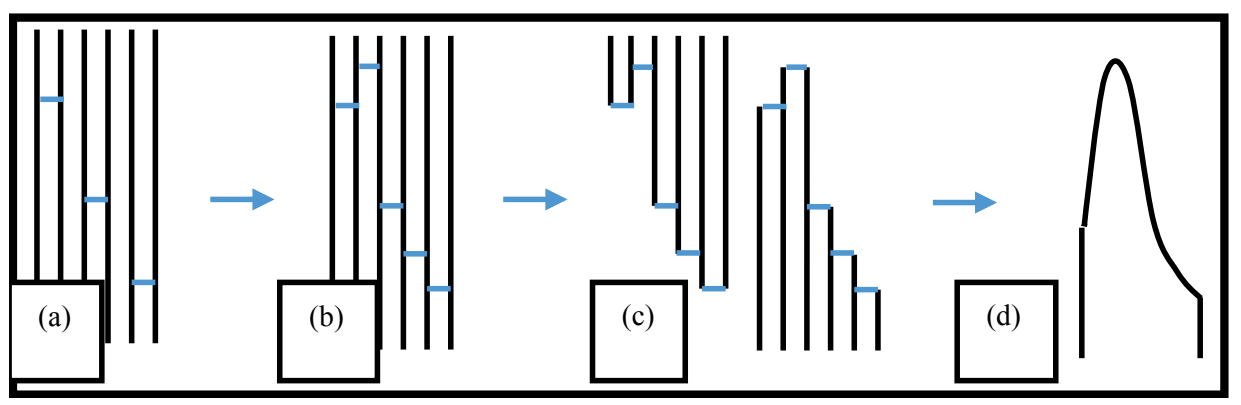

Figure 4: Schematic illustration of fibre fibrillar failure. ${ }^{9}$
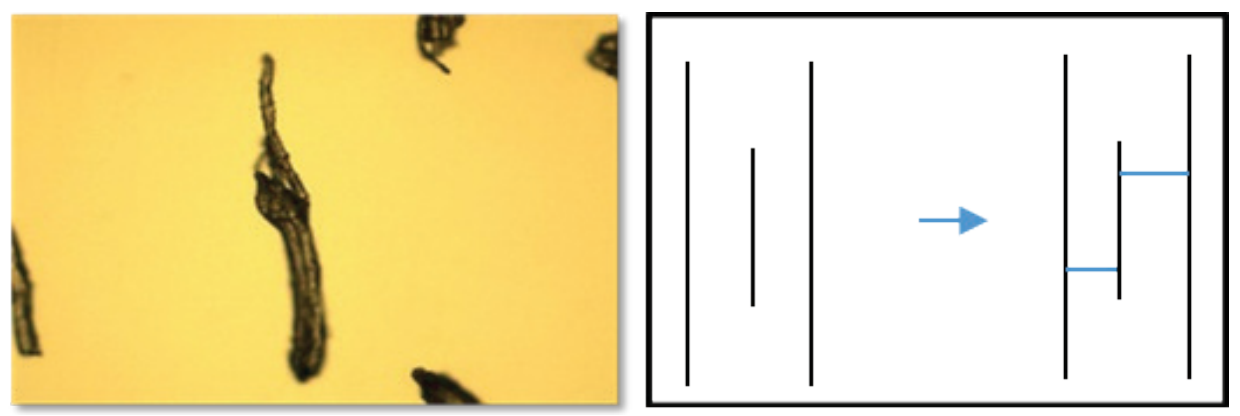

Figure 5: Fibre end step brake failure using optical microscope with $10 \times$ magnification. Step brake failure illustration for fibre granular fracture. ${ }^{9}$

Surface shear from pulverised blades might cause fibre peel off on the fibre surface. The cause of this fibre failure was initiated with shear force that applied onto the fibre that forming a crack below the surface of the fibre. Prolong shear on the fibre, makes the crack run along the fibre fibril and continually peel off the other fibril in the fibre as in Figure 6(e). Eventually, these fibrils splitting causing cross section reduction in fibre at the end of the pulverise process. ${ }^{9,10}$ Practically, the reduction of fibre area indicate that low cellulose content that strengthening the fibre. Hence, fibre peel off can caused reduction of fibre's strength when stress applied as it produced imperfect fibre condition. Socket brake cut (Figure 6[f]) that caused from chemical fibre degradation were experienced by fibre that treated with sodium hydroxide and aminosilane. Sodium hydroxide that used to roughen the fibre surface for interlocking mechanism between fibre and matrix ${ }^{1,11,13-15}$ was probable cause for this fibre failure. Prolong sodium hydroxide treatment initiate small crack on the fibre surface. ${ }^{15}$ 
(a)

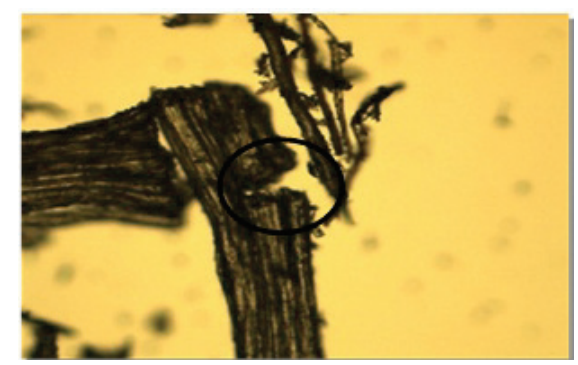

(c)



(e)

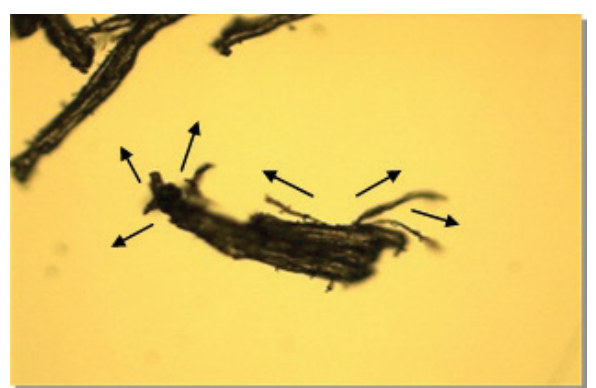

(b)

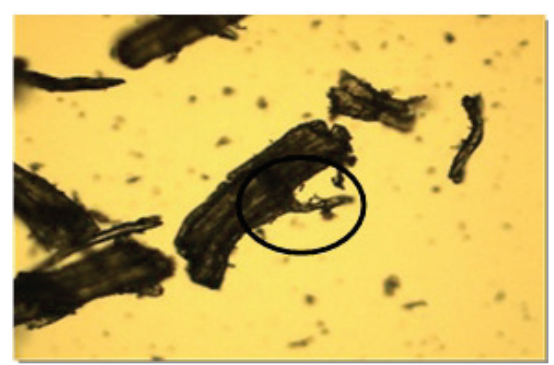

(d)

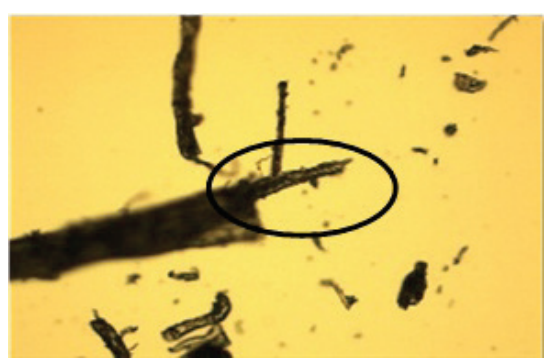

(f)

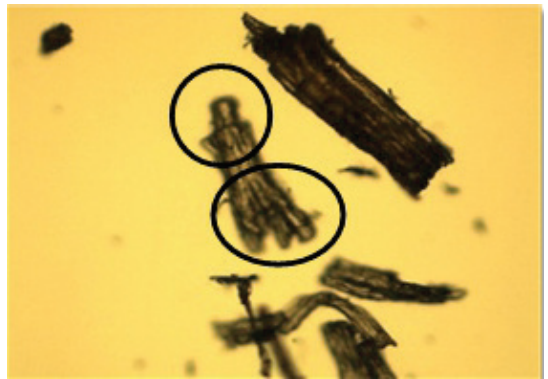

Figure 6: Tensile fatigue failure sequence: (a) fibre transverse crack, (b) fibre axial split, (c) fibre with middle diameter reduction (d) fibre failure with reduce in crosssection, (e) surface fibre peel off splitting with multidirectional direction, (f) chemical degraded fibre breakage and biaxial failure, using polarised microscope with $10 \times$ magnification.

Biaxial rotation failure as in Figure 6(f) occurred as fibre middle area bends and rotated bidirectional in clockwise and anti-clockwise at both fibre ends. Initially, the fibre crack in axial direction when repeated rotations were applied at fibre ends. Bundle of fibrils that attached strongly were split slightly at fibre middle parts. Further repeated rotations, break outer fibrils layer and break the inner fibrils with wide multiple splitting. ${ }^{9,10}$ The fibre cracked on fibre surface and, weaken fibre structure bonding after the occurrence of socket brake cut and 
biaxial rotation at fibre end respectively; might contribute to the faster composite failure during testing. It might reduce the composite's stress properties but in other hand, it can improved the elastic properties of the composite sample.

\subsection{Composite Board}

In order to prove the existence of these fibre failures from pulverised fibre, the compressed kenaf/unsaturated polyester composite was analyse under polarised microscope using $20 \times$ magnification.
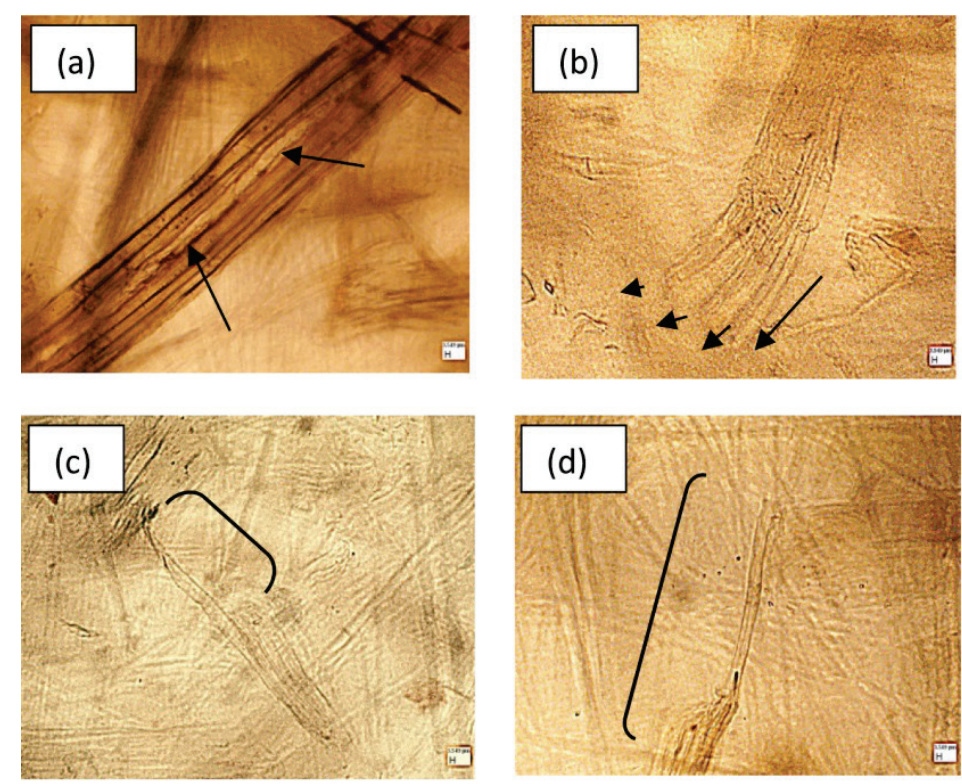

Figure 7: Fibre long axial splits at (a) middle and (b) fibre edge, (c) fibrillar failure, (d) granular fracture for stepped break failure, (e) fibre transverse crack, (f) fibre axial splits, (g) fibre with middle diameter reduction, (h) fibre failure with reduce in cross section, (i) surface fibre peel off, (j) chemical degraded fibre brake and (k) biaxial failure, using polarised microscope with $20 \times$ magnification. (continued on next page) 

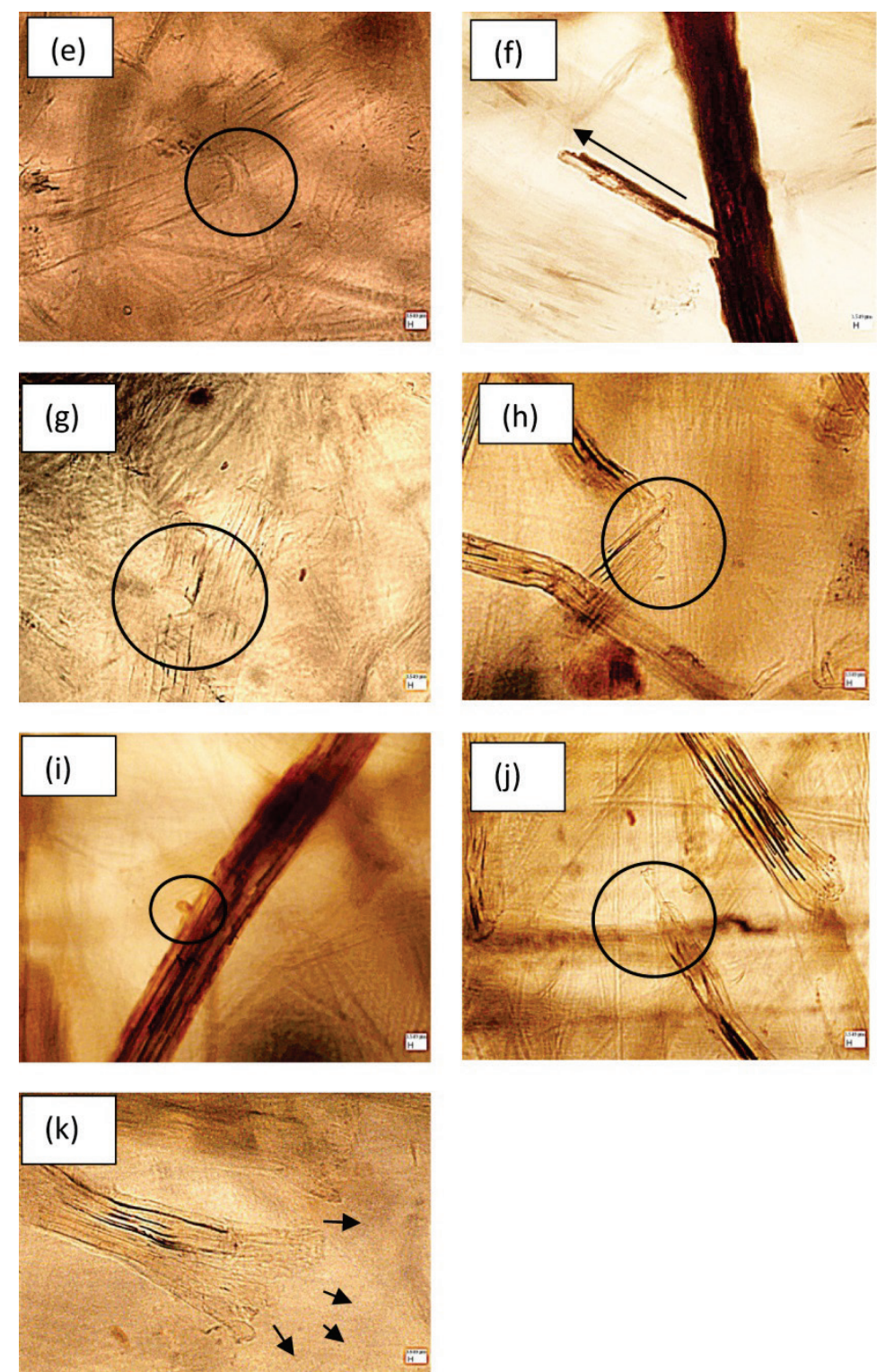

Figure 6: (continued)

\section{CONCLUSION}

The effect of fibre length and aspect ratio to the mechanical properties of kenaf/unsaturated polyester composite were studied. The behaviour of tensile sample fracture area with the correlation with fibre condition after pulverise 
process is been considered. It identified that, condition of the fibre failure is crucial in reinforcing mechanism of the composite. The results shows that there are seven identified fibre failure of kenaf fibre after pass through pulverise processes. This including fibre axial splits, fibrillar failure, granular fracture, fatigue failure, fibre peel off, chemical degraded fibre brake and biaxial failure which contribute to the composite properties. The combination of individual fibre contact area, interphase factor and optimise fabrication process are crucial to produce superior properties of short fibre reinforce composite. In conclusion, by knowing the fibre failure behaviour, the cause of inconsistency of natural fibre based composite strength can be resolved.

\section{ACKNOWLEDGEMENT}

The author is gratified for the financial support by the Universiti Teknologi MARA. We also would like to thank Polymer Composites Research Laboratory, Centre of Polymer Composites Research and Technology, Institute of Science, Universiti Teknologi MARA for the calibrated facilities.

\section{REFERENCES}

1. Aji, I. et al. (2009). Kenaf fibres as reinforcement for polymeric composites: A review. Int. J. Mech. Mat. Eng., 4(3), 239-248.

2. Le Duc, A., Vergnes, B. \& Budtova, T. (2011). Polypropylene/natural fibres composites: Analysis of fibre dimensions after compounding and observations of fibre rupture by rheo-optics. Composites, Part A, 42(11), 1727-1737, https://doi.org/10.1016/j.compositesa.2011.07.027.

3. Hull, D. \& Clyne, T. (1996). An introduction to composite materials. 2nd ed. Victoria, Australia: Cambridge University Press, https://doi.org/10.1017/CBO9781139170130.

4. Iyer, K. A. \& Torkelson, J. M. (2014). Green composites of polypropylene and eggshell: Effective biofiller size reduction and dispersion by single-step processing with solid-state shear pulverization. Compos. Sci. Technol., 102, 152-160, https://doi.org/10.1016/j. compscitech.2014.07.029.

5. Riedel, U. \& Nickel, J. (2004). Applications of natural fiber composites for constructive parts in aerospace, automobiles, and other areas. In Biopolymers online. Weinheim, Germany: Wiley-VCH Verlag GmbH \& Co. KGaA. 
6. Barakat, A., de Vries, H. \& Rouau, X. (2013). Dry fractionation process as an important step in current and future lignocellulose biorefineries: A review. Bioresour. Technol., 134, 362-373, https://doi.org/10.1016/j. biortech.2013.01.169.

7. Herrera-Franco, P. J. and Valadez-González, A. (2005). A study of the mechanical properties of short natural-fiber reinforced composites. Composites, Part B, 36(8), 597-608, https://doi.org/10.1016/j. compositesb.2005.04.001.

8. Kardos, J. (1985). Critical issues in achieving desirable mechanical properties for short fiber composites. Pure Appl. Chem., 57(11), 16511657, https://doi.org/10.1351/pac198557111651.

9. Schulz, E. (1991). Fibre failure and wear of materials. An atlas of fracture. Fatigue and durability. Von J. W. D. Hearle, B. Lomas, W. D. Cooke und I. J. Duerden. Chichester: Ellis Horwood Ltd. Publisliers 1989. 454 S., geb., £ 79.35. Acta Polym., 42(4), 192, https://doi.org/10.1002/actp.1991.010420418.

10. Elices, M. \& Llorca, J. (2002). Fiber fracture. Oxford: Gulf Professional Publishing.

11. Ho, M. et al. (2012). Critical factors on manufacturing processes of natural fibre composites. Composites, Part B, 43(8), 3549-3562, https://doi.org/10.1016/j.compositesb.2011.10.001.

12. Faruk, O. et al. (2012). Biocomposites reinforced with natural fibers: 2000-2010. Prog. Polym. Sci., 37(11), 1552-1596, https://doi.org/10.1016/j.progpolymsci.2012.04.003.

13. Malhotra, N., Sheikh, K. \& Rani, S. (2012). A review on mechanical characterization of natural fiber reinforced polymer composites. JERS, $3(1), 75-80$.

14. Chauhan, A., Chauhan, P. \& Kaith, B. (2012). Natural fiber reinforced composite: A concise review article. J. Chem. Eng. Process Technol., 3(2), 132, https://doi.org/10.4172/2157-7048.1000132.

15. Aziz, S. H. \& Ansell, M. P. (2004). The effect of alkalization and fibre alignment on the mechanical and thermal properties of kenaf and hemp bast fibre composites: Part 1; Polyester resin matrix. Compos. Sci. Technol., 64(9), 1219-1230, https://doi.org/10.1016/j.compscitech. 2003.10.001. 